\title{
BURNS-PHYSIOTHERAPY'S CHALLENGE
}

Author: SUSAN KEAYS, B.Sc. Physio. (Rand), Physiotherapist Baragwanath Hospital.

This paper was read at the Jubilee Congress of the South African Society of Pliysiotherapy, July 1975 . in Jolnanneshurg. are:

The aims of physiotherapy in the treatment of burns

(1) To prevent chest complications and bed sores.

(2) To prevent contractures.

(3) To prevent hypertrophic scare formation.

(4) To encourage re-epithelialization and decrease sepsis.

(5) To encourage and motivate the patients and help them to help themselves, remembering that because of the fear of movement associated with burns, few patients realise what they are able to do. Considerable time should be spent explicining procedures to the patient.

This paper (originally illustrated by 68 slides) deals with the methods found of value in achieving these aims at Baragwanath Hospital. where approximately 400 major burns are treated every ye.ir.

\section{The Prevention of Chest Complications.}

Chest complications may result from

(i) Inhalation burns leading to pulmonary oedema

(ii) Septic foci in the lung consequent on septicaemia. Septicaemia is mest frequently seen in chest burns.

(iii) Hypostatis resulting from pain and decreased chest movement, leading to the collection of mucus, atelectasis and possibıy pneumonia. This is the type that physiotherapy aims primarily to prevent.

Burns of the chest present certain problems to the therapist: Percussion. vibration. trachea pressing and resisted inspiratory exercises are ofter. impossible. (Fig. $1)$.

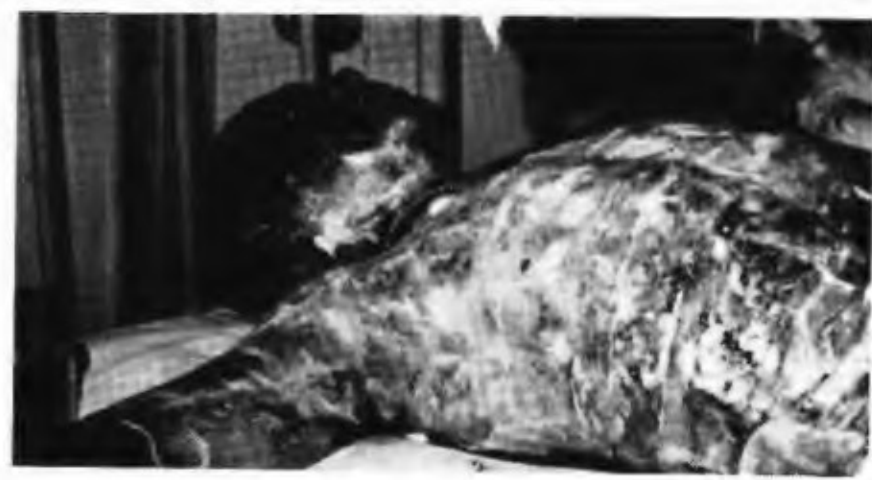

Fig. 1. Extensive full thickness burns of the chest. Note "tulle-gras" dressing used post-grafting.
Treatment includes:

Deep breathing exercises in the form of prolong expiratory exercises.

- Use of a Bennet respirator using a mucolytic age and with the respirator set patient-triggered.

- Postural drainage. This does not interfere with flut intake. In some centres patients with burns of th head and neck are not posturally drained becaus this is considered to increase oedema.

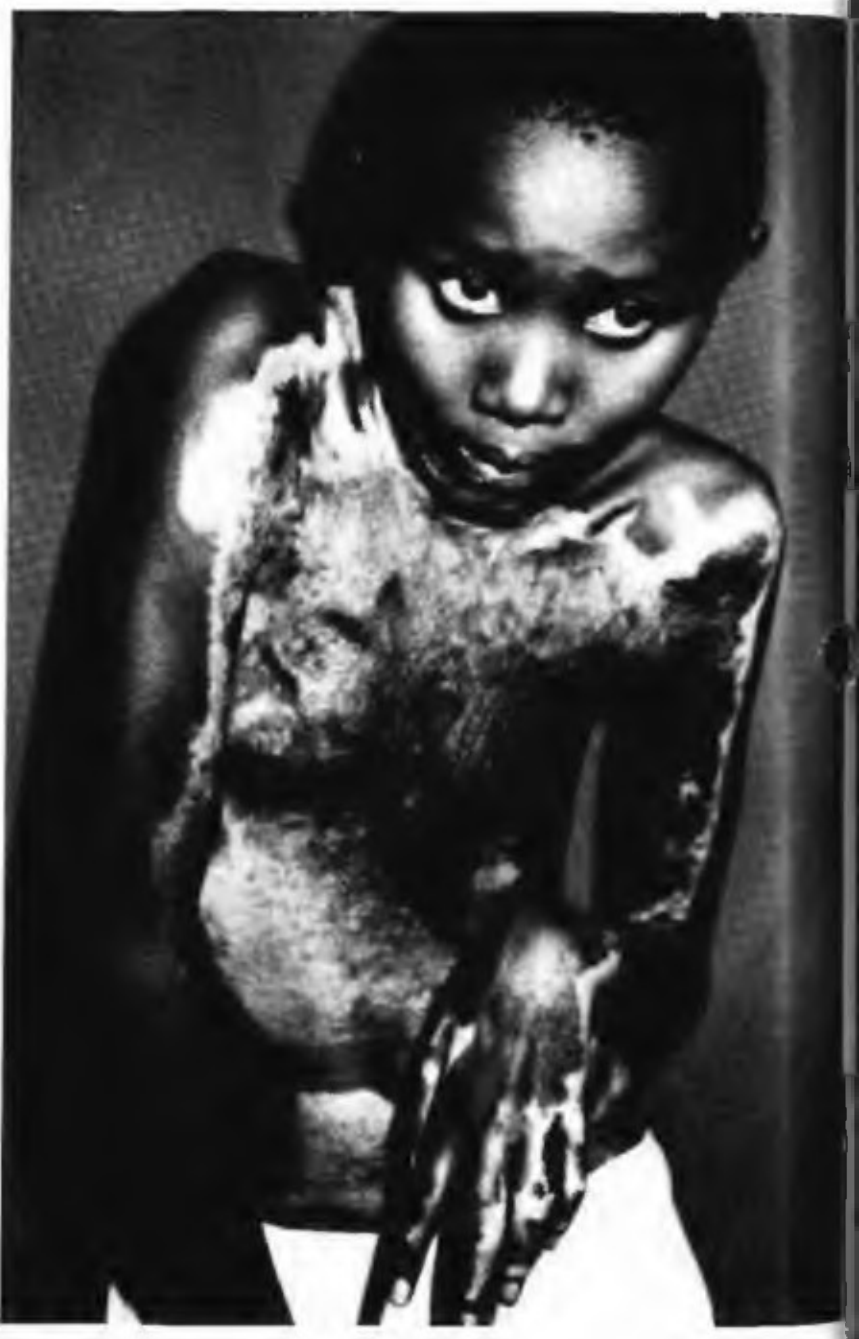

Fig. 2. Typical contractures, neck flexion, shoulder adduction, elbow and wrist flexion and M.P. extensios (untreated by physiotherapy). 
Frequent and vigorous coughing and

An awareness of the possible complications and An aw assessment by the therapist are very important in the prevention of chest complications.

I. The Prevention of Bed Sores:

- Severely burnt patients are treated on air beds.

- Patients are taught bridging.

- They are got out of bed as soon as the temperature is normal and the haemoglobin is within normal range. The patient must be feeling well with no signs of toxaemia or septicaemia.

If lower limbs are involved, firm bandaging (tubigrip stretched crepe bandages) is necessary to prevent hydrostatic oedema, blistering and ulceration.

Repeated posture correction is necessary.

Farly mobilization is of particular value in order to to a saline bath. where dressings are soaked off and go to a done in the most pain-free way.

Care should be taken that the patient does not exerience unnecessary cold as burnt patients have tremendous difficulty making up heat loss.

III. The Prevention of Contractures - The second and challenging aim to the physiotherapist.

Contractures showing the dynamic influence of gravity include neck flexion. shoulder adduction. wrist ficxion. metacarpo-phalangeal extension (Fig. 2) and ankle planmetacion. Hips, knees and elbows most typically adopt flexed postures in response to pain

Methods of preventing contractures include

\section{Positioning \\ Exercise \\ Splintage.}

General Principles Followed in the Above Methods:

(1) Pre-grafting therapy commences 24 hours post injury. Post-grafting therapy commences 48 hours after surgery. Therapy continues for up to six months in the cases of deep dermal and full thickness burns

(2) Positioning is maintained wherever the patient is in bed, unless limbs are in use for functional activities. Exercises are done where possible in conjunction with the bath-dressing routine.

Full range. free active or assisted exercises are most efficiently done in water or in fresh dressings (dry dressings are extremely painful) twice daily. Functional exercises are essential.

(4) Splints are made using plaster of paris; they are well lined, light. comfortable. well moulded and do not resirict function. Splints are routinely made for necks. hands and feet. They are made 24 hours after admission and worn for up to six months. Post-grafting new splints may be applied in theatre. If not splinted in the theatre. splints are usually re-applied 5-10 days later depending on the area of grafting.

(5) Limbs are splinted so as to maintain that end of the range most susceptible to contractures and exercised so as to maintain the opposite range.

(6) Each patients is different and has varying requirements. A programme is selected on admission and re-evaluated regularly.

Several factors influence the therapist in maintaining joint range:

(l) Co-operation of the patien'i.
(2) The severity of the burn, i.e. depth, surface area and degree of joint involvement. It may be necessary to request analgesia, which is given in the form of $15 \mathrm{mg}$ Omnipon or up to $50 \mathrm{mg}$ Pethidine. However, this is not routinely necessary.

(3) The type of dressing. Restrictive dressings like crepe or gauze bandages limit the patient tremendously. Pre-grafting the dressing of cheice is tulle-gras, cotton gauze soaked in eusol and iurgifix to maintain the dressing in place (or plasti: bags for hands).

Post-grafting the dressing of croice is a single layer of tulle-gras.

The methods of Positioning

Exercising

Splintage

will be discussed for each joint in the body.

\section{THE NECK}

The most typical contracture is flexion, associated sometimes with side flexion or rotation (Fig. 3).

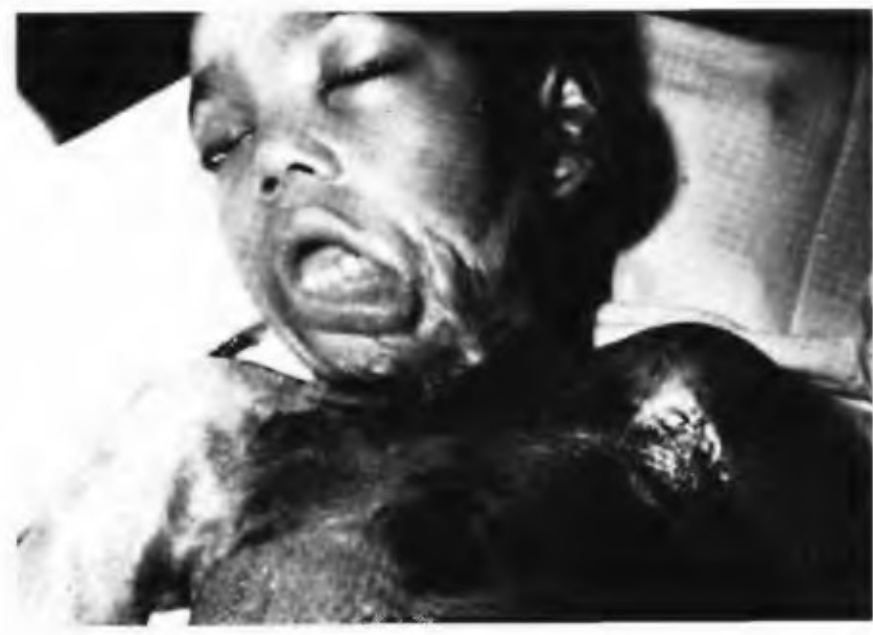

Fig 3. Typical untreated contraction of neck showing flexion, side flexion and rotation with lip involvement. Note hypertrophic scar formation on chin and neck.

\section{Positioning}

The neck is positioned in extension using one or two pillows or folded towels placed under the shoulders. This is essential from the day of admission for at least six months post-injury.

\section{Exercising}

Exercise5. where possible. are done in conjunction with the bath dressing routine. and include

-. Free active. full range of all movements done in front of a mirror.

- Sup. str. ly: H. unsupported N. ext. over bed. (Fig. 4)

\section{Splintage}

Necks are splinted in slight extension using plaster of paris collars. The collars are made in sitting as this has been found to be the most effective way. They are well moulded and lined with thin foam sponge or cotton wool. The burn is protected with plastic covering during the making. 


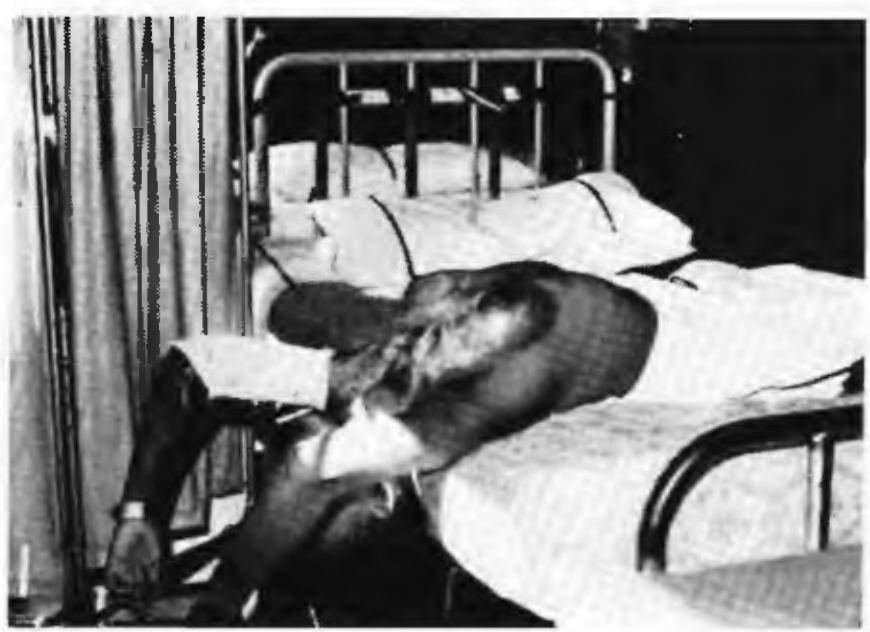

Fig. 4. Stretching exercises for neck and shoulder burns. Note the patient's range of movement three weeks post deep dermal burns.

Collars are worn whenever the patient is up out of bed or sitting and should also bc worn whilst in bed if positioning is not adequately mainiained.

Collars may be removed for eating. They are not worn for 10 days post-grafting. The patient continues to wear the collar for at least six months post injury.

\section{THE SHOULDER}

The most typical contracture is adduction.

\section{Positioning}

Shoulders are positioned in $90-100^{\circ}$ of abduction. They are held in position by straps attaching the wrist to horizontal drip stands. (Fig. 5)

The hands are free in order for the patient to remove the attachment and use the hand for functional activities.

\section{Exercises}

In conjunction with the bath dressing routine include:

- Free active (usually assisted in axillary burns) exercises of all movements through full range.

- St; Alt. Sh. flex, and ext. using pulley.

- St; Sh. flex. and elevation to creep fingers up wall.

- Str. st: hg. from top of open docr

- Sup. Str. ly; 4 unsupported Sh. flex. and elevation. (Fig. 4)

\section{Splintage}

Shoulder abduction splints interfere considerably with function and for this reason are not routinely ordered for co-operative patients. Unco-operative patients initially require well-moulded plaster of paris splints and later aeroplane splints made by orthopazdic workshops.

\section{THE ELBOW}

The most common contracture is flexion but elbows are the most unpredictable joints and careful observation and daily assessment are essential. Initially elbows assume a slightly flexed and pronated position. Later the pattern of contracture tends to vary more according to the surface area burnt.

\section{Positioning}

Initially in extension and supination on a pillow and assisted by the strap should the shoulder be involved (Fig. 5) At the therapist's discretio:n positioning in flexion (the more functional position) or alternately in flexion and extension in the case of bilateral elbow involvement may be necessary. (Fig. 5)

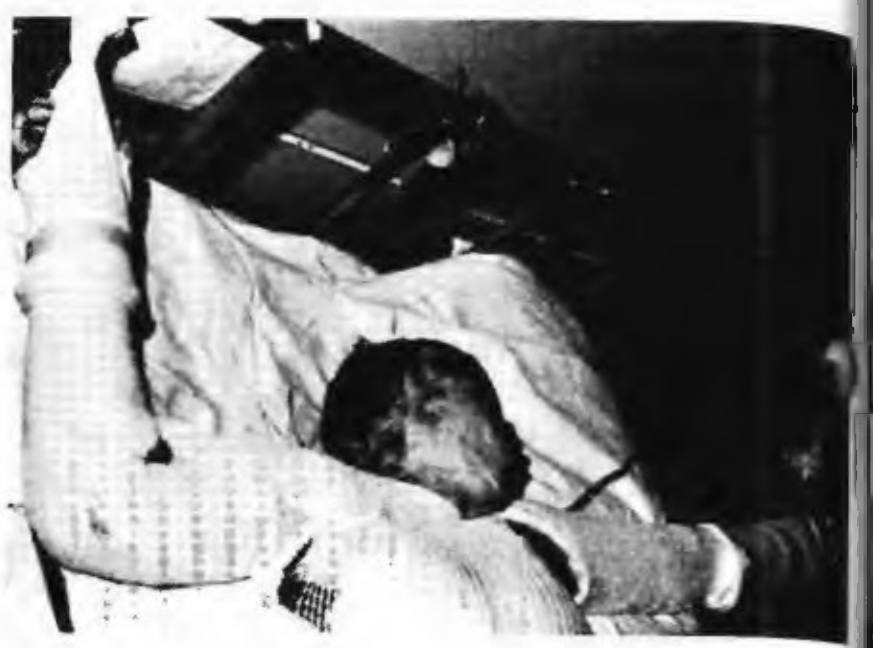

Fig. 5. Positioning for shoulder and elbow burns. Note: Dressing is pre-grafting type of "tulle-gras" cotton wool and surgifix.

\section{Exercises}

- Free active or assisted full range twice daily of all movements.

- Rch. sup. st: Elb. flex. and ext.

\section{Splintage}

This is not necessary in all cases. If necessary elbows may be splinted in extension. flexion or alternately in flexion and extension according to the therapist's assessment.

\section{HANDS}

The most typical contractures are wrist flexion. metacarpophalangeal extension, interphalangeal flexion and thumb adduction. One of the reasons for this typical deformity is due to the fact that the co-lateral ligaments have tightened in their shortened position.

Hands are routinely treated in ster:le plastic bags or gloves which collect fluid (up to $400 \mathrm{cc}$ in 24 hours). Allowing for far easier and more pain-free movement and full function. (Fig. 6) Bags are changed $2 \mathrm{X}$ daily in order to prevent sepsis.

\section{Positioning}

Initially swollen burnt hands are elevated on pillows.

\section{Exercises include}

- Free active full range of all movements both in and out of saline baths. (Fig. 7)

- Functional activities include eating. bed making. dressing and assisting one another 


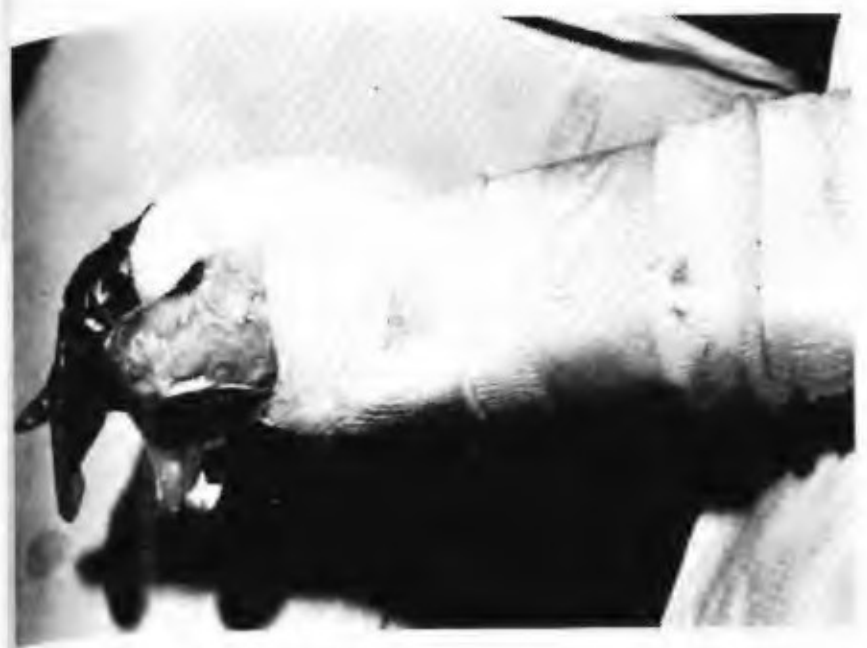

q. 6. Burnt hand treated in plastic glove and dorsiflexion splint.

Splinting

The application of plastic bags and the collection of fuid encourages wrist flexion. It is most essential to accompany plastic bags with dorsiflexion splints which, at the same time as dorsiflexing the wrist. bring the metacarpophalangeal joints into flexion. (Fig. 6) Great care should be taken to ensure that the splint only reaches the mid-palmar crcase and that ihe thenar eminence is iree. Dorsiflexion splints are worn during the day and at night. Occasionally thumb abduction splints are necessary. At a later stage flexor burns of the palm may require a lively-wire type splint in order to prevent flexor contractures
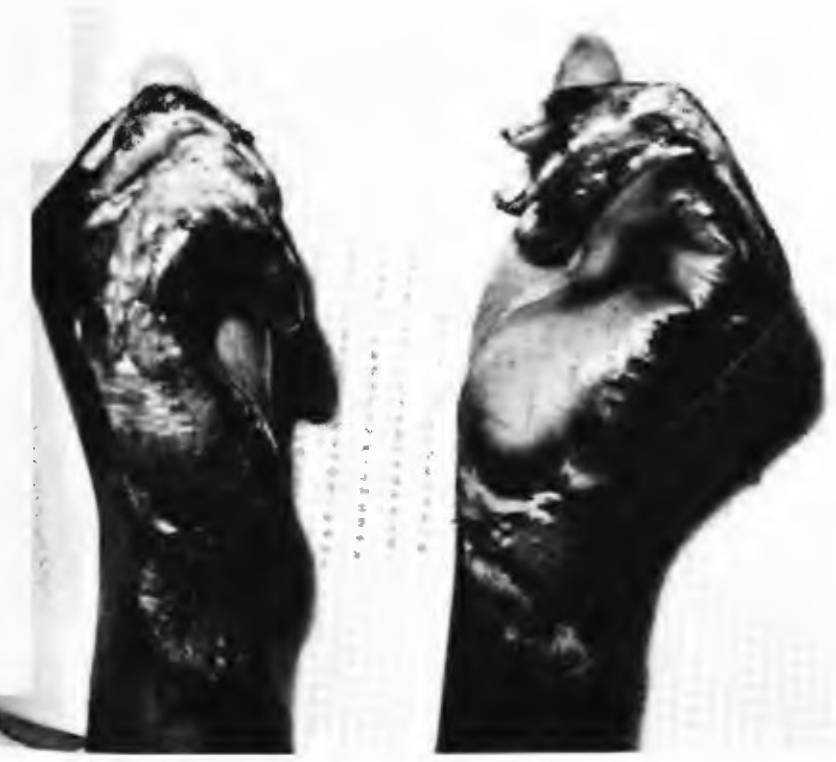

Fig. 7. Hand exercises three days post mesh-grafting. Note: Almost full flexion obtained.

\section{HIPS}

Hips tend to contract in flexion. These are the least commonly burnt joints seen at Baragwanath but present some of the most serious problems.

\section{Positioning}

In prone (pair: permitting) or supine with legs straight. (Fig. 8)

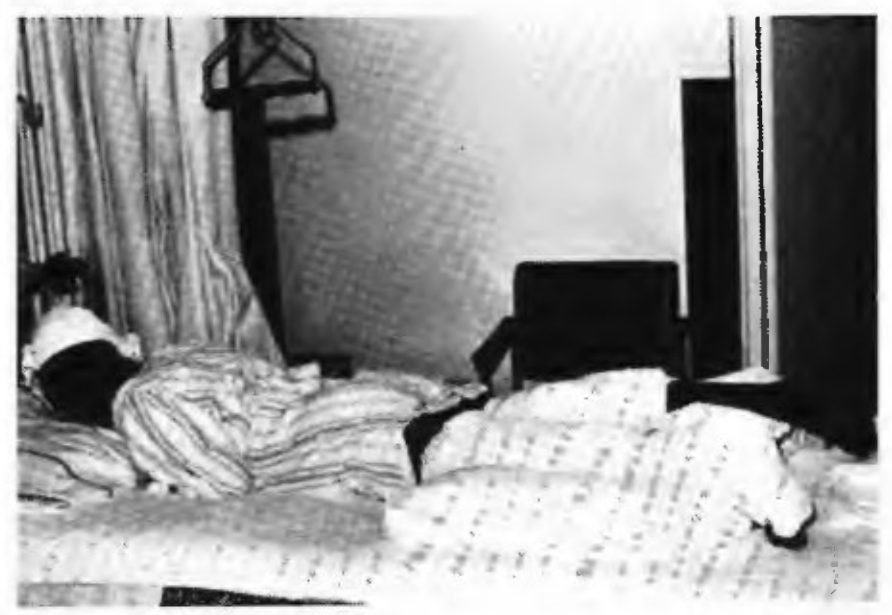

Fig. 8. Positioning for hips and knees and splinting for knees and ankles.

Exercises include

- Full range active or assisted for ail hip movements. - Walking, wearing crepe bandages or tubigrip to prevent oedema.

\section{Splintage}

Usually unnecessary in hip burns, otner than hip spicas occasionally for children.

\section{KNEES}

The typical knee deformity is flexion.

\section{Positioning}

In prone or supine with knees in exte; sion. (Fig. 8)

Exercises include

-- Free active or assisted flexion and extension both out and in saline baths.

- Step st: K. flex and ext.

\section{Splintage}

Extension splints may be necessary in unco-operative patients. (Fig. 8)

\section{ANKLES}

The typical contracture is plantarflexion.

\section{Positioning}

Ankles held in dorsiflexion using plaster of paris splints. (Fig. 8)

Exercises include

- Free active or assisted full range of all movements.

- Walking wearing tubigrip or crepe bandaging.

\section{Splintage}

Dorsiflexion splints are routinely made and worn at all times except when walking. 


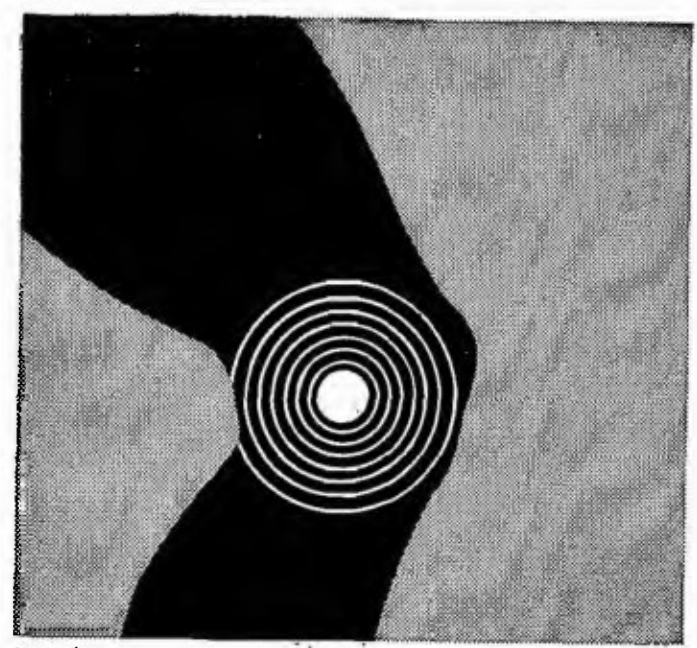

1. Rheumatic pains in joints and muscles

3. Muscle cramps and stiffness

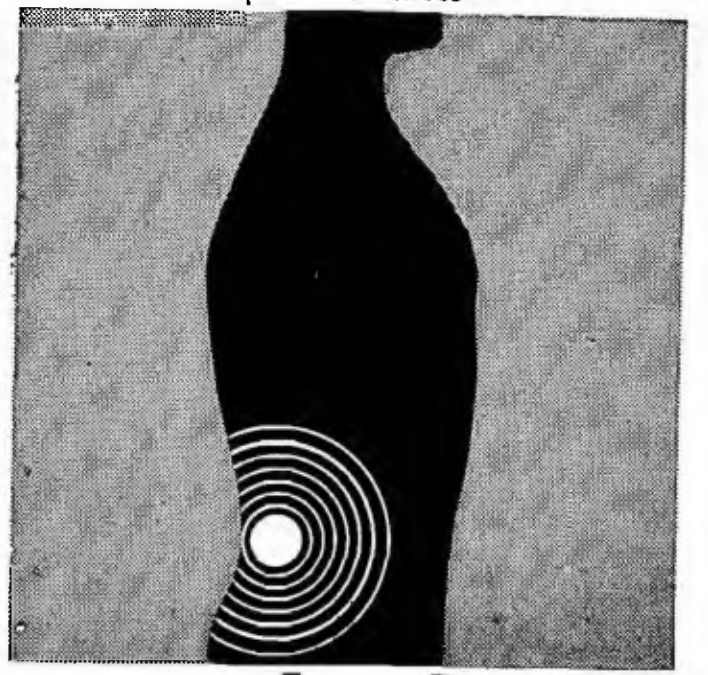

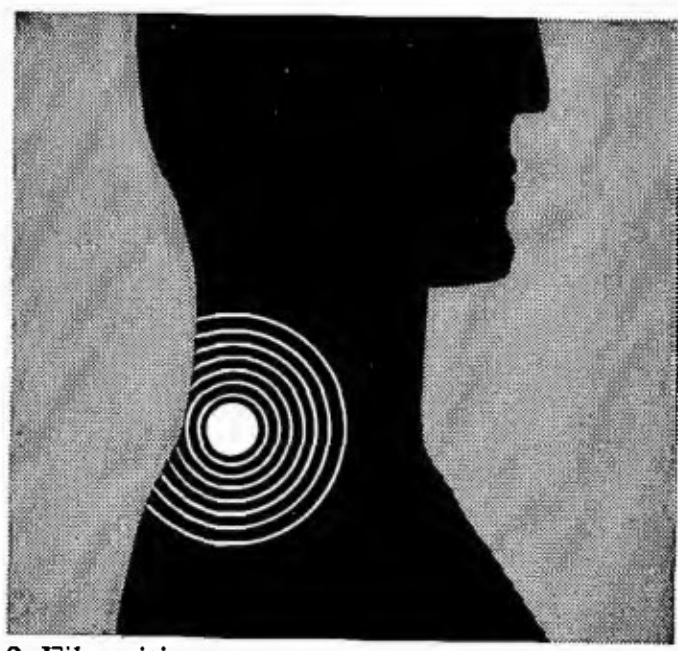

2. Fibrositis

4. Other local pains and aches
Formula:

Diethylamine

Salicylate $10 \mathrm{~g}$

Nopoxamine $1 \mathrm{~g}$

Excipient q.s.ad. $100 \mathrm{~g}$

pain is our scene...

\section{analgen ointment}

Formulation: Two pain-killing ingredients, diethylamine salicylate and nopoxamine, in a special ointment base to speed subcutaneous penetration.

Indications: Rheumatic pains in joints and muscles, low backache, fibrositis, sprains and bruises, muscular cramps and stiffness, neuralgic pains.

Action: Soothing, deep-penetrating, rapid pain relief with local anaesthetic effect.

Application: Massage gently into the skin around the affected area until completely absorbed. Apply as often as required.
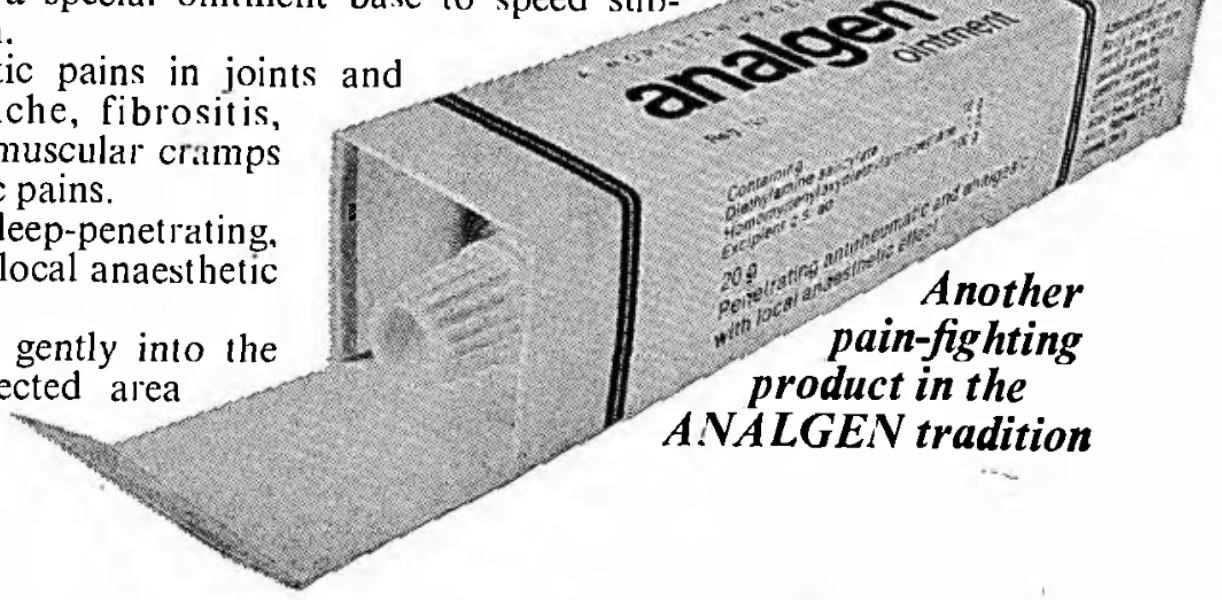
III The Prevention of Hypertrophic Scar Formation. (See Fig. 3)

Compression bandaging in the form of tubigrip is aplied immediately after grafts have taken in order to applient hypertrophic scar formation. These are worn preven six months to two years. They are replaced every rom weeks to one month. This form of compression, three wer with massage and ultrasound, are of value in reducing already developed hypertrophic scare.

IV. The fourth aim of physiotherapy is to encourage re-epithelialization and decrease sepsis. UVL is used for this purpose.

In superficial and deep dermal burns an $\mathrm{El}$ is given daily to regranulating areas.

In full thickness burns an E3-E4 given daily to areas of gross slough. Sloughs come away spontaneously after 14 days post burr. UVL accelerates desloughing and acilitates early grafting.

UVL has been found to be most effective in the treatment of burns.

v. The final aim is to encourage and motivate the patient and with the co-operation of the doctors, nurses, occupational therapist and the patient, to return him to his previous home and working situation. At all times one must be aware that the patient is not merely a series of burnt joints but a whole being whose rehabilitation is an exciting challenge to the physiotherapist.
I should like to thank Mr. Hume Maxwell, Mr. Sidney Hersh, Irene Kallis (occupational therapist) and the physiotherapists at Baragwanath Hospital for their help and encouragement in the preparation of this paper.

\section{BIBLIOGRAPHY}

(1) Baebel, S., Bulkley, A., and Shuck, J. Physical Therapy for Burned Patients. Physical Therapy Vol. 32 No. 12, December 1973.

(2) Jaeger, M. A. Maintenance of Function of the Burn Patient. Physical Therapy Vol. 52 No. 6, June 1972.

(3) Lavore, J. S., and Marshall, J. H. Expedient Splinting of the Burned Patient. Physical Therapy Vol. 52 No. 10, October 1972.

(4) Trussell, E. C., and Hayne, C. R. Physiotherapy in the Treatment of Burns and Plastic Surgery. Physiotherapy March 1970.

(5) Gronley, J. K. Early Intensive Therapy for the Burned Hand. Physical Therapy Vol. 44 No. 10, October 1964.

(6) Brett, M. L. Treatment of Burns at Red Cross War Memorial Children's Hospital, Cape Town. South African Journal of Physiotherapy, April 1966.

(7) Runnalls, M. J., and Stephan, M. W. The Use of Entonox in Conjunction with the Physiotherapy Treatment of Burns. South African Journal of Physiotherapy, June 1973.

(8) Holland, E. J. The Role of Physical Therapy in the Rehabilitation of Burned Patients. Physical Therapy Vol. 32 No. 5, May 1952.

\section{BIGGER AND BRIGHTER EASTER STAMPS THIS YEAR}

- The Easter Stamps which are being released in a new Eries by the National Council for the Care of Cripples in South Africa throughout the Republic and South West Africa for its Easter Stamp Campaign this year, are bigger and brighter than any of the stamps used during these annual campaigns over the past few years. The bigger stamps compensate for the fact that they are now limited to 10 per set and that they will be sold at 2 cents each. They are brighter because they have been printed on an exceptionally white gummed paper.

Ten beautiful South African wild flowers appear on these larger stamps in full colour. They can be obtained in strips of 10 and in sheets of 50 or 100 stamps. Interesting details about each flower in the series are supplied with each set of 10 stamps on information sheets which are supplied gratis to purchasers of stamps. These details were compiled in co-operation with eminent botanists.

These attractive new Easter Stamps will be sold at selling points in cities and towns and also at Cripple Care offices. They may also be ordered on application from: The Director, National Council for the Care of Cripples in South Africa, P.O. Box 10173, Johannesburg 2000.

This year's Easter Stamp Fund Campaign is regarded as one of the most vital in the history of Cripple Care in South Africa. There is a real danger that a shortage of funds will compel the National Council to curtail its activities in order to remain viable in the present unfavourable economic climate. This could hold serious repercussions for the welfare of the large and growing number of cripples of all races in this country. The danger can be averted only if sufficient funds can be raised during the forthcoming campaign.

The National Council and its nine constituent Cripple Care Associations have, therefore, decided to concentrate more intensively on the campaign than ever before. They are confident of greater support from a responsible and sympathetic public to ensure that a shortage of funds will not endanger the welfare of cripples or increase their suffering.

Please buy more Easter Stamps this year! 